\title{
Combustion behavior and kinetics of low-lipid microalgae via thermogravimetric analysis
}

\author{
Chao Gai ${ }^{a}$, Zhengang Liu ${ }^{\mathrm{a}, *}$, Guanghua Han ${ }^{\mathrm{b}}$, Nana Peng ${ }^{\mathrm{a}}$, Aonan Fan ${ }^{\mathrm{a}, \mathrm{c}}$ \\ ${ }^{a}$ Research Center for Eco-Environmental Sciences, Chinese Academy of Sciences, 18 Shuangqing Road, Beijing 100085, PR China \\ ${ }^{\mathrm{b}}$ Department of Industrial and Systems Engineering, National University of Singapore, Singapore 117576, Singapore \\ ' School of Chemistry and Chemical Engineering, Ningxia University, Yinchuan 750021, PR China
}

\section{H I G H L I G H T S}

- Combustion of low-lipid microalgae C. pyrenoidosa and S. platensis were studied.

- Chemical functional groups present in two microalgae were investigated via FTIR.

- Apparent activation energies for combustion of the two microalgae were calculated.

- C. pyrenoidosa has a higher reactivity compared to S. platensis during combustion.

\section{A R T I C L E I N F O}

\section{Article history:}

Received 9 December 2014

Received in revised form 5 January 2015

Accepted 9 January 2015

Available online 22 January 2015

\section{Keywords:}

Microalgae

Combustion

Thermogravimetric analysis

Apparent activation energy

Kinetics

\begin{abstract}
A B S T R A C T
Thermogravimetric analysis and differential thermal analysis were employed to investigate combustion characteristics of two low-lipid microalgae, Chlorella pyrenoidosa (CP) and Spirulina platensis (SP) and isoconversional Starink approach was used to calculate the kinetic parameters in the present study. The results showed that three stages of mass loss, including dehydration, devolatilization and char oxidation, were observed during combustion of both of two low-lipid microalgae. The whole weight loss of combustion of two microalgae was both shifted to higher temperature zones with increased heating rates from 10 to $40 \mathrm{~K} / \mathrm{min}$. In the $0.1-0.9$ conversion range, the apparent activation energy of $\mathrm{CP}$ increased first from 51.96 to $79.53 \mathrm{~kJ} / \mathrm{mol}$, then decreased to $55.59 \mathrm{~kJ} / \mathrm{mol}$. Finally, it slightly increased to $67.27 \mathrm{~kJ} / \mathrm{mol}$. In the case of SP, the apparent activation energy gradually increased from 68.51 to $91.06 \mathrm{~kJ} / \mathrm{mol}$.
\end{abstract}

(c) 2015 Elsevier Ltd. All rights reserved.

\section{Introduction}

Primary fossil energy sources such as coal, petroleum and natural gas have become gradually exhausted over the past several decades, contributing to the development of clean, renewable energy sources like wind, solar and biomass. Converting biomass to biofuels has become one of the hotspots in the field of renewable energy, in terms of biodiesel and bioethanol production from crop plants. It has made a great contribution to the world energy consumption, but this research drew some criticism because it will encroach on arable land and affect food commodity prices. Alternatively, microalgae grow in freshwater/marine systems and there is no requirement for land, which has been gradually recognized as potential feedstocks for the next generation of biofuels and chemical (Williams and Laurens, 2010; Anastasakis and Ross, 2011;

\footnotetext{
* Corresponding author at: 18 Shuangqing Road, Beijing 100085, PR China. Tel.: +8610 62912718; fax: +861062912718.

E-mail address: zgliu@rcees.ac.cn (Z. Liu).
}

López-González et al., 2014). Several possible pathways for converting microalgae to bioenergy have been investigated, mainly including biochemical conversion like anaerobic digestion and alcoholic fermentation, thermochemical conversion such as combustion, pyrolysis, gasification and liquefaction (Rizzo et al., 2013; Gai et al., 2014; Stucki et al., 2009).

Combustion of biomass has recently gained much attention due to their fuel flexibility, high heat-transfer and combustion efficiency (Magdziarz and Wilk, 2013). Compared to lignocellulosic biomass, microalgal biomass have lower decomposition temperatures during the combustion process, which means higher reactivity and lower operational costs. One of the reasons is due to the different major components. Proteins, lipids and carbohydrates are the major composition of microalgae, which are less thermal resistant that the main components of lignocellulosic biomass in terms of cellulose, hemicellulose and lignin (López-González et al., 2014). Another reason is that the relatively high ash content of microalgae was observed to have a catalytic effect in the decomposition process. However, the industrial problems in terms of 
slagging and fouling brought by the high ash content during combustion should not be overlooked either. Washing with water has been verified to alleviate such problems. For example, Fahmi et al. (2007) concluded that washing with water could remove up to $70 \%$ of the alkali metals during the pyrolysis and combustion of grasses. Teng and Wei (1998) investigated the influence of water treatment on pyrolysis of rice hulls and reported the same conclusion. Centrifugation can also decrease the ash content in microalgae before the energy production. Chen et al. (2014) reported that ash content of wastewater with centrifugation was reduced from $28.6 \%$ to $18.6 \%$. Additionally, the relatively high content of nitrogen due to the presence of proteins in microalgae compared to lignocellulosic biomass may render high emissions of $\mathrm{NO}_{x}$ during combustion. The adoption of proper gas cleaning and catalytic treatment systems of the flue gas are required (Rizzo et al., 2013).

To help design and scale-up of the industrial combustor/gasifier, a knowledge of the kinetics of the combustion process is essential, which is usually investigated via thermogravimetric analysis (TGA) and differential thermal analysis (DTA). TGA and DTA are very useful tools for assessing the thermal characteristics of biomass and its components under a controlled environment and is often associated with kinetic modeling (Magdziarz and Wilk, 2013; Branca and Di Blasi, 2015). Numerous papers have concerned with the kinetics of combustion of lignocellulosic biomass, in terms of rice husk (Saldarriaga et al., 2015), corn straw (Fang et al., 2013), miscanthus (Jayaraman and Gökalp, 2015) and date palm wastes (Sait et al., 2012). Despite the literatures regarding lignocellulosic biomass is abundant, only a limited number of studies are concerned about the combustion of microalgae.

High-lipid microalgae have been main feedstocks in the production of biofuels, especially algae-to-biodiesel technology (Williams and Laurens, 2010). High-lipid microalgae mean a lipid accumulation in microalgae under a stressed condition such as nitrogen depletion. It will sacrifice biomass productivity, reduce the net energy yield, and make the process very sensitive to contamination (Yu et al., 2011). According to Williams and Laurens (2010), high lipid containing algae may not necessarily be the most favorable candidate organisms. Compared with high-lipid algae, low-lipid algae typically have a higher biomass yield and can grow in harsher environments. Thus it has a greater potential for biofuel production but less attention has been paid to this kind of microalgae. The aim of this study was to study the combustion characteristics of lowlipid microalgae by TGA-DTA technique. Chlorella pyrenoidosa (CP) and Spirulina platensis (SP) were selected due to their low-lipid content. Iso-conversional method was adopted to determine the kinetic parameters for the thermal decomposition process.

\section{Methods}

\subsection{Materials and characterization}

CP and SP were purchased from a health food store as food-grade material (NOW FOODS, Bloomingdale, IL). The dry solid content was calculated as the dry residue at $105^{\circ} \mathrm{C}$ for $24 \mathrm{~h}$. The ash content was determined as the solid residue after the combustion of feedstock at $575^{\circ} \mathrm{C}$ for $3 \mathrm{~h}$. The elemental analyzer (CE-440, Exeter Analytical Inc., North Chelmsfor, MA) was employed to determine carbon, hydrogen and nitrogen contents of the feedstock. The contents of crude protein, crude fat, and carbohydrate were measured by the Kjeldahl method, Soxhlet extraction, and phenol-sulfuric acid method, respectively (Yu et al., 2011). The proximate analysis, elemental composition and chemical composition of microalgae samples are shown in Table 1.

The possible functionalities present in the two low-lipid microalgae were investigated via FTIR technique. The FTIR spectra was collected using a Thermo Nicolet Nexus 670 Fourier Transform Infrared Spectroscopy (FTIR). With a model of Transmission E.S.P., $0.5 \mathrm{~cm}^{-1}$ resolution, 128 scans adsorption interferogram were collected in the $4000-750 \mathrm{~cm}^{-1}$ wavelength for each spectra.

\subsection{Apparatus and procedures}

Combustion characteristics of two low-lipid microalgae were analyzed by a thermogravimetric analyzer (TGA-Q50, TA Instruments, New Castle, DE) at air atmosphere. To minimize the effects of mass and heat transfer limitation, very small sample sizes (about $10 \mathrm{mg}$ ) were loaded into the ceramic crucible. All combustion experiments were conducted at atmospheric pressure, using temperature ranging from ambient temperature to $1073 \mathrm{~K}$ with different heating rate $(10,20,30$ and 40$)$ and air flux of $20 \mathrm{ml} /$ min. Each experiment was repeated twice to guarantee the data repeatability.

\section{Results and discussion}

\subsection{Infrared spectra of $C P$ and $S P$}

Infrared spectra of the two low-lipid microalgae (CP and SP) are available in Supplementary data. The locations of adsorption peaks for the two microalgae are identical, suggesting the types of functionalities of the two microalgae does not make too much differences. The prominent adsorption peaks at $1800-1500 \mathrm{~cm}^{-1}$ suggest the presence of proteins (Phukan et al., 2011), consistent with the relative high content of proteins for the two microalgae. The carbonyl stretching $\mathrm{C}=\mathrm{O}$ appeared at $1647 \mathrm{~cm}^{-1}$ is related to amide-I bonds while the $\mathrm{C}-\mathrm{N}$ stretching and $\mathrm{N}-\mathrm{H}$ bending at $1533 \mathrm{~cm}^{-1}$ are ascribed to amide-II bonds. Both peaks suggest the presence of peptide bond between two amino acid molecules. Small adsorption peaks could be observed at $3100-2800 \mathrm{~cm}^{-1}$, which is ascribed to $-\mathrm{CH}_{2}$ stretching in lipids. The peaks at $2928 \mathrm{~cm}^{-1}$ and $2860 \mathrm{~cm}^{-1}$ indicate the asymmetric and symmetric vibration of $-\mathrm{CH}_{2}$ stretching in lipids. These peaks for lipids are not as prominent as that of proteins, consisting with the analysis of chemical composition in Table 1 that both materials are low-lipid microalgae. In addition, some adsorption peaks are observed at $1200-900 \mathrm{~cm}^{-1}$, which is ascribed to the stretching $\mathrm{C}-\mathrm{O}, \mathrm{C}-\mathrm{C}$, $\mathrm{C}-\mathrm{O}-\mathrm{C}$ and $\mathrm{C}-\mathrm{O}-\mathrm{P}$, confirming the presence of certain nonfibrous carbohydrates in the two microalgae.

\subsection{Combustion characteristics}

The TG-DTG-DTA curves for the combustion of CP and SP at the heating rate of $10 \mathrm{~K} / \mathrm{min}$ are presented in Fig. 1. Based on the formation of pronounced peaks in TG-DTG-DTA curves, it can be seen that both two low-lipid microalgae exhibited three stages of weight loss during the combustion process. To be specific, the first stage (stage I) was from ambient temperature to around $400 \mathrm{~K}$, which is a dehydration process as described by various literature (Agrawal and Chakraborty, 2013; Rizzo et al., 2013). A slight endothermic peak appeared in this stage from DTA curves of CP and SP, indicating the evaporation of moisture from the microalgae. The second mass loss stage (stage II) started at around $400 \mathrm{~K}$ and ended at about $650 \mathrm{~K}$. It is related to the devolatilization of main components of microalgae including protein, lipid and non-fibrous carbohydrates and the formation of chars. This stage has an exothermic peak in DTA curve, suggesting that the devolatilization of volatile components of microalgae releases a large amount of heat. The third stage (stage III) was ranged from approximate 700-1000 K, corresponding to a process of exothermic char oxidation. 
Table 1

Characteristics of CP and SP.

\begin{tabular}{|c|c|c|c|c|c|c|c|c|}
\hline & C. pyrenoidosa & S. platensis & & C. pyrenoidosa & S. platensis & & C. pyrenoidosa & S. platensis \\
\hline \multicolumn{3}{|c|}{ Proximate analysis (wt.\% $\mathrm{db}^{\mathrm{a}}$ ) } & \multicolumn{3}{|c|}{ Elemental composition (wt.\% daf ${ }^{\mathrm{b}}$ ) } & \multicolumn{3}{|c|}{ Chemical composition ( daf $^{\mathrm{b}}$ ) } \\
\hline Dry solid $\left(a r^{c}\right)$ & 93.3 & 93.8 & Carbon & 51.2 & 49.6 & Protein & 71.5 & 64.7 \\
\hline Moisture $\left(\operatorname{ar}^{c}\right)$ & 6.7 & 6.2 & Hydrogen & 6.8 & 6.2 & Lipid & 0.2 & 4.8 \\
\hline Volatile solid & 94.4 & 90.3 & Nitrogen & 11.3 & 10.8 & Non-fibrous & 22.5 & 19.3 \\
\hline Ash content & 5.6 & 9.7 & Oyxgen $^{\mathrm{d}}$ & 30.7 & 33.4 & Carbohydrates & & \\
\hline
\end{tabular}

a Dry basis.

b Dry and ash free basis.

c As received basis.

d By difference.

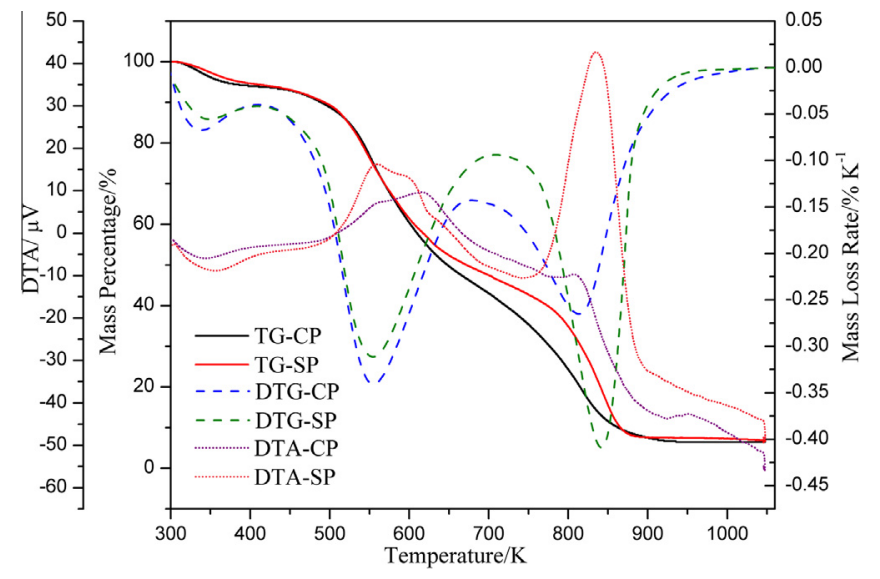

Fig. 1. Typical TG-DTG-DTA curve of combustion of $C P$ and SP at the heating rate of $10 \mathrm{~K} / \mathrm{min}$.

Some difference could be observed in the TG-DTG-DTA curves between CP and SP. For the major mass loss of stage II, the maximum mass loss rate of CP is higher than that of SP while SP is higher than that of $\mathrm{CP}$ for the stage III. These differences are mainly attributed to the different compositions of protein, lipid and nonfibrous carbohydrates in two microalgae illustrated in Table 1. Furthermore, it can be seen in Table 1 that both CP and SP contain high content of proteins, which are composed of different types and quantities of amino acids. According to the differential enthalpie analysis of amino acids carried out by Olafsson and Bryan (1970), the decomposition temperatures of different amino acids are not identical. The last decomposition step (stage III) is mainly attributed to the decomposition of inorganic material (López-González et al., 2014). It can be seen in Table 1 that SP almost has twice as much of ash content than that of $\mathrm{CP}$, which is mainly due to the high alkali metal content in the feedstock (Kay, 1991). Previous studies (Liden et al., 1998; Czernik and Bridgwater, 2004) showed that sodium, potassium, magnesium and silicate in ash significantly affect pyrolysis degradation of biomass material, while potassium, sodium, calcium and magnesium are the main components influencing the combustion process. According to Kay (1991), the content of potassium, sodium, calcium and magnesium of SP is higher than that of $\mathrm{CP}$. The high contents of these metals increase the rate of degradation and as a result, the maximum mass loss rate of SP is higher than that of CP for the stage III. In addition, the stage III of char oxidation is also affected by the char yield. Similarly, Fahmi et al. (2007) investigated the effect of alkali metals on combustion of grass samples and it was observed that the char yield from combustion increased as alkali metals increased.

According to EI May et al. (2012), during combustion process the sample burning at lower temperatures and shorter time exhibits higher reactivity. Overall, the combustion characteristics of $\mathrm{CP}$ are higher than that of SP from the difference mentioned above. It should be noted that emissions of $\mathrm{NO}_{x}$ and $\mathrm{SO}_{2}$ are one of the major problems during the combustion of CP and SP due to the high content of nitrogen from protein in the two microalgae. Addition of organic calcium compounds (OCCs) has been proved to be a feasible method to simultaneously remove such pollutant emissions during the combustion of lignocellulosic biomass (Zhang et al., 2015). It is expected to further improve the combustion behavior of CP and SP using OCCs, which is recommended for further study.

\subsection{Effect of heating rate}

The TG-DTG curves for the combustion of CP and SP under different heating rates are illustrated in Figs. 2 and 3. To illustrate
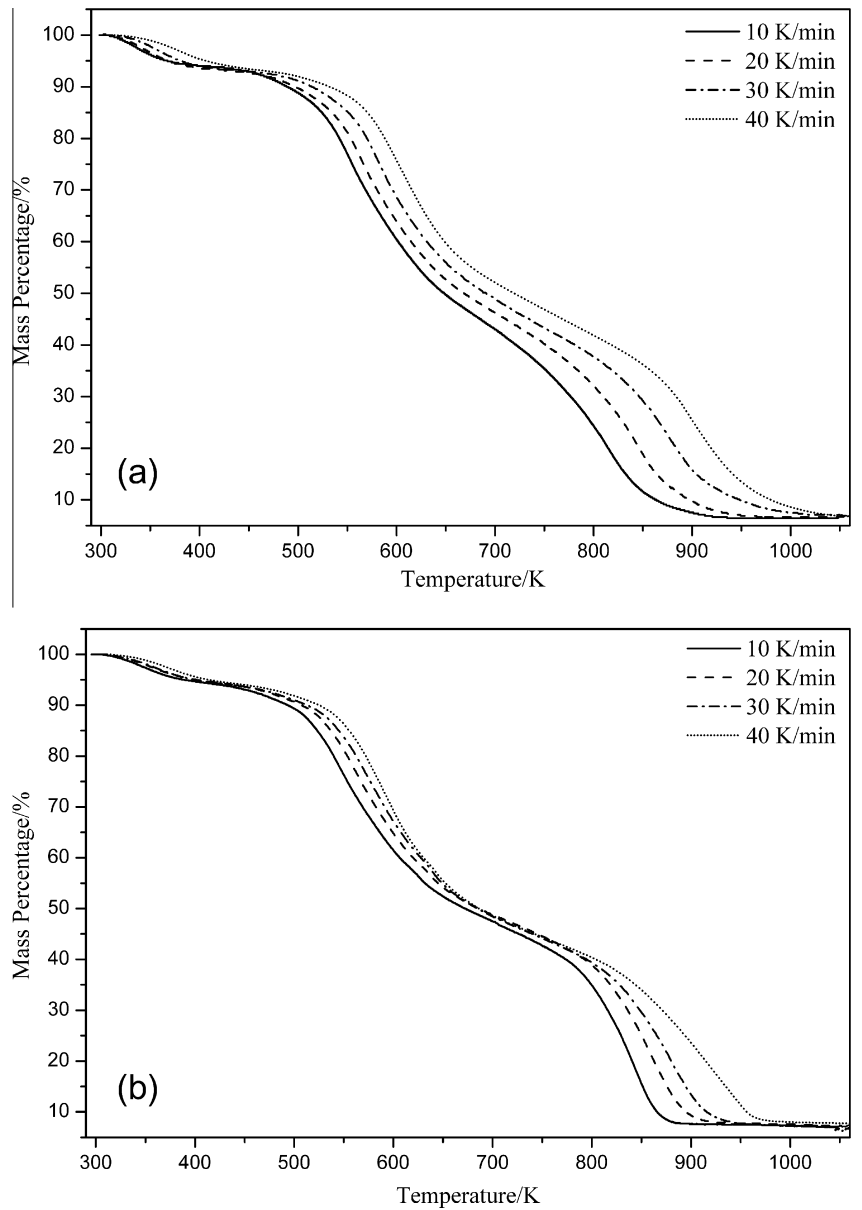

Fig. 2. TG curves for the combustion of $\mathrm{CP}(\mathrm{a})$ and $\mathrm{SP}(\mathrm{b})$ at the heating rate of 10 , $20,30,40 \mathrm{~K} / \mathrm{min}$ 

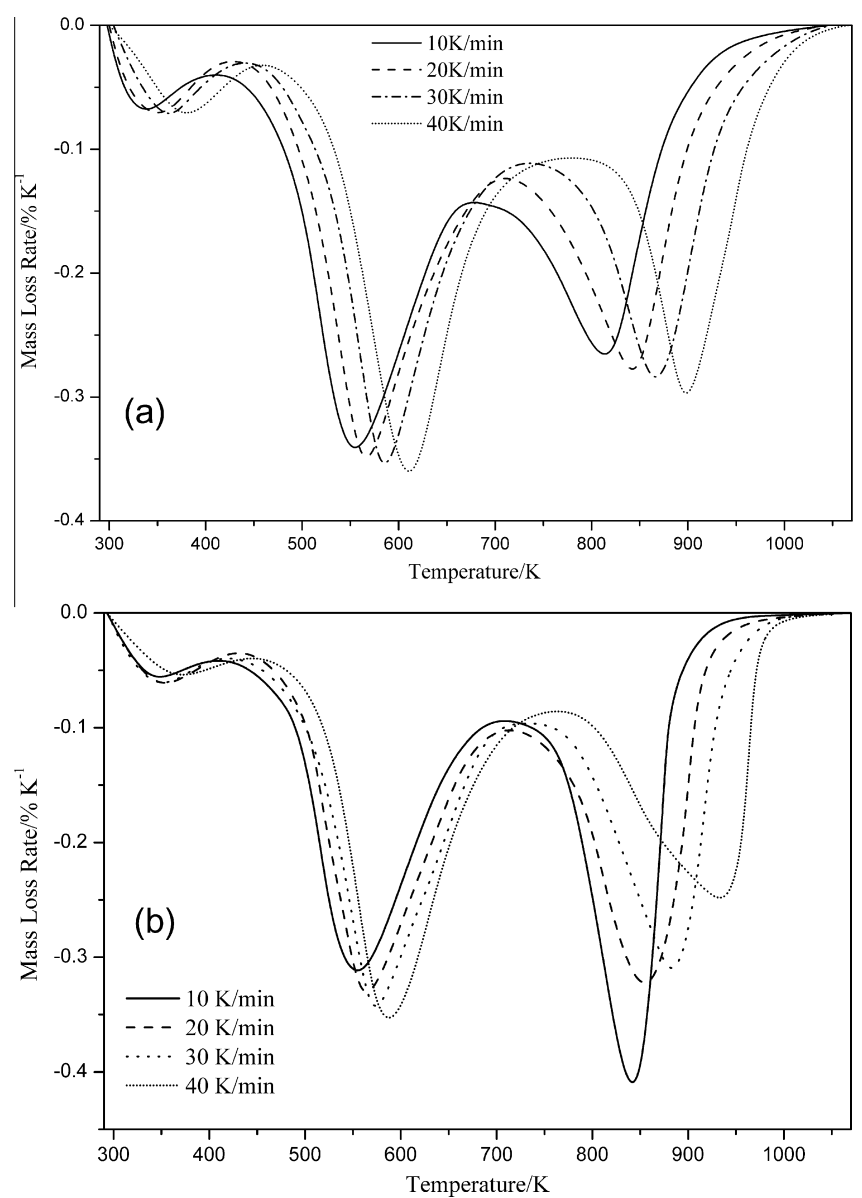

Fig. 3. DTG curves for the combustion of $\mathrm{CP}(\mathrm{a})$ and $\mathrm{SP}(\mathrm{b})$ at the heating rate of 10 , $20,30,40 \mathrm{~K} / \mathrm{min}$.

the effect of heating rates on the combustion process, characteristic parameters derived from the TG-DTG curves are presented in Table 2. It can be observed in Figs. 2 and 3 that the whole weight losses during the combustion process for CP and SP was both shifted to higher temperature zones with increasing the heating rates from 10 to $40 \mathrm{~K} / \mathrm{min}$. In case of stage I, the temperature of the maximum rate of mass loss $\left(T_{\mathrm{p}}, \mathrm{K}\right)$ was increased from $338 \mathrm{~K}$ to $379 \mathrm{~K}$ for $\mathrm{CP}$ and $349 \mathrm{~K}$ to $381 \mathrm{~K}$ for SP, respectively. During stage II, $T_{\mathrm{p}}$ was increased from $556 \mathrm{~K}$ to $610 \mathrm{~K}$ for $\mathrm{CP}$ and $553 \mathrm{~K}$ to $588 \mathrm{~K}$ for SP. As for stage III, $T_{\mathrm{p}}$ was gradually increased from $813 \mathrm{~K}$ to $898 \mathrm{~K}$ for $\mathrm{CP}$ and $842 \mathrm{~K}$ to $933 \mathrm{~K}$ for SP, respectively. In addition, the temperature of initial ignition $\left(T_{\mathrm{i}}\right)$ and final burnout $\left(T_{\mathrm{f}}\right)$ for any stage of $\mathrm{CP}$ and SP both increased gradually with the increment of heating rate. It is mainly attributed to the increased temperature gradient throughout the cross-section of the sample at higher heating rates, which affected the heat transfer between the thermogravimetric instrument and sample. Similar results were reported by combustion of microalgal biomass such as Chlorella vulgaris (Chen et al., 2013) and Nannochloropsis oculta (Ali et al., 2015) and lignocellulosic biomass such as switch grass (Chandrasekaran and Hopke, 2012), and eucalyptus wood (López-González et al., 2013).

In stage I of dehydration, no obvious impact of heating rate was observed on the variation of maximum mass loss rate $\left(-\mathrm{DTG}_{\max }\right.$, $\% / \mathrm{K}$ ) for CP and SP. As for the stage II of devolatilization, the value of $-\mathrm{DTG}_{\max }$ for CP and SP were both gradually from $0.340 \% / \mathrm{K}$ and $0.312 \% / \mathrm{K}$ to $0.359 \% / \mathrm{K}$ and $0.352 \% / \mathrm{K}$, respectively. It showed the same trend with combustion of $C$. vulgaris (Agrawal and Chakraborty, 2013). However, the variation of $-\mathrm{DTG}_{\max }$ for $\mathrm{CP}$ and SP is different for the stage III of char oxidation. The value of - DTG $_{\max }$ of CP was always increased from $0.265 \% / \mathrm{K}$ to $0.295 \% / \mathrm{K}$, while in case of SP, the value of $-\mathrm{DTG}_{\max }$ was decreased from $0.410 \% / \mathrm{K}$ to $0.247 \% / \mathrm{K}$. It may be due to the different catalytic effects of ash for CP and SP at different heating rates and further investigation regarding this issue is needed in future study.

In terms of HTZ (i.e., the full temperature width at half-maximum of the value of, $-\mathrm{DTG}_{\max } \mathrm{K}$ ), it was gradually increased from $78 \mathrm{~K}$ for $\mathrm{CP}$ and $106 \mathrm{~K}$ for SP to $95 \mathrm{~K}$ and $137 \mathrm{~K}$, respectively. In stage II and stage III, the heating rate has different effects on the value of HTZ. As for CP, it was gradually decreased from $124 \mathrm{~K}$ for stage II and $177 \mathrm{~K}$ for stage III to $104 \mathrm{~K}$ and $145 \mathrm{~K}$, respectively. The value of HTZ of SP was conversely increased from $120 \mathrm{~K}$ for stage II and $78 \mathrm{~K}$ for stage III to $131 \mathrm{~K}$ and $146 \mathrm{~K}$, respectively. The heating rate was observed to have the same effect on the variation of the total mass loss (ML, \%) for CP and SP. In stage I,

Table 2

Characteristic parameters for the combustion process of $\mathrm{CP}$ and SP.

\begin{tabular}{|c|c|c|c|c|c|c|c|c|c|c|c|c|c|}
\hline \multirow[t]{2}{*}{ Sample CP } & \multicolumn{6}{|c|}{ Stage I } & \multirow[t]{2}{*}{ Sample SP } & \multicolumn{6}{|c|}{ Stage I } \\
\hline & $T_{\mathrm{i}}(\mathrm{K})$ & $T_{\mathrm{f}}(\mathrm{K})$ & $T_{\mathrm{p}}(\mathrm{K})$ & $-\mathrm{DTG}_{\max }(\% / \mathrm{K})$ & HTZ(K) & ML (\%) & & $T_{\mathrm{i}}(\mathrm{K})$ & $T_{\mathrm{f}}(\mathrm{K})$ & $T_{\mathrm{p}}(\mathrm{K})$ & $-\mathrm{DTG}_{\max }(\% / \mathrm{K})$ & HTZ(K) & ML (\%) \\
\hline $10 \mathrm{~K} / \mathrm{min}$ & 298 & 401 & 338 & 0.067 & 78 & 5.975 & $10 \mathrm{~K} / \mathrm{min}$ & 298 & 402 & 349 & 0.056 & 106 & 5.346 \\
\hline $20 \mathrm{~K} / \mathrm{min}$ & 298 & 418 & 350 & 0.069 & 82 & 6.604 & $20 \mathrm{~K} / \mathrm{min}$ & 298 & 405 & 354 & 0.061 & 110 & 5.460 \\
\hline $30 \mathrm{~K} / \mathrm{min}$ & 298 & 431 & 362 & 0.069 & 84 & 6.918 & $30 \mathrm{~K} / \mathrm{min}$ & 298 & 420 & 365 & 0.063 & 132 & 5.546 \\
\hline $40 \mathrm{~K} / \mathrm{min}$ & 298 & 454 & 379 & 0.072 & 95 & 7.103 & $40 \mathrm{~K} / \mathrm{min}$ & 298 & 429 & 381 & 0.054 & 137 & 5.672 \\
\hline \multirow[t]{2}{*}{ Sample CP } & \multicolumn{6}{|c|}{$\underline{\text { Stage II }}$} & \multirow[t]{2}{*}{ Sample SP } & \multicolumn{6}{|c|}{ Stage II } \\
\hline & $T_{\mathrm{i}}(\mathrm{K})$ & $T_{\mathrm{f}}(\mathrm{K})$ & $T_{\mathrm{p}}(\mathrm{K})$ & $-\mathrm{DTG}_{\max }(\% / \mathrm{K})$ & $\mathrm{HTZ}(\mathrm{K})$ & ML (\%) & & $T_{\mathrm{i}}(\mathrm{K})$ & $T_{\mathrm{f}}(\mathrm{K})$ & $T_{\mathrm{p}}(\mathrm{K})$ & $-\mathrm{DTG}_{\max }(\% / \mathrm{K})$ & $\operatorname{HTZ}(\mathrm{K})$ & ML (\%) \\
\hline $10 \mathrm{~K} / \mathrm{min}$ & 419 & 672 & 556 & 0.340 & 124 & 47.16 & $10 \mathrm{~K} / \mathrm{min}$ & 421 & 703 & 553 & 0.312 & 120 & 45.18 \\
\hline $20 \mathrm{~K} / \mathrm{min}$ & 437 & 709 & 567 & 0.347 & 122 & 47.39 & $20 \mathrm{~K} / \mathrm{min}$ & 435 & 715 & 565 & 0.331 & 125 & 46.86 \\
\hline $30 \mathrm{~K} / \mathrm{min}$ & 449 & 728 & 586 & 0.353 & 119 & 47.67 & $30 \mathrm{~K} / \mathrm{min}$ & 440 & 724 & 574 & 0.343 & 129 & 47.79 \\
\hline $40 \mathrm{~K} / \mathrm{min}$ & 463 & 766 & 610 & 0.359 & 104 & 48.24 & $40 \mathrm{~K} / \mathrm{min}$ & 457 & 751 & 588 & 0.352 & 131 & 49.37 \\
\hline \multirow[t]{2}{*}{ Sample CP } & \multicolumn{6}{|c|}{ Stage III } & Sample SP & \multicolumn{6}{|c|}{ Stage III } \\
\hline & $T_{\mathrm{i}}(\mathrm{K})$ & $T_{\mathrm{f}}(\mathrm{K})$ & $T_{\mathrm{p}}(\mathrm{K})$ & $-\mathrm{DTG}_{\max }(\% / \mathrm{K})$ & $\mathrm{HTZ}(\mathrm{K})$ & ML (\%) & & $T_{\mathrm{i}}(\mathrm{K})$ & $T_{\mathrm{f}}(\mathrm{K})$ & $T_{\mathrm{p}}(\mathrm{K})$ & $-\mathrm{DTG}_{\max }(\% / \mathrm{K})$ & $\mathrm{HTZ}(\mathrm{K})$ & ML (\%) \\
\hline $10 \mathrm{~K} / \mathrm{min}$ & 685 & 1039 & 813 & 0.265 & 177 & 38.36 & $10 \mathrm{~K} / \mathrm{min}$ & 714 & 1020 & 842 & 0.410 & 78 & 39.31 \\
\hline $20 \mathrm{~K} / \mathrm{min}$ & 714 & 1048 & 842 & 0.276 & 161 & 37.42 & $20 \mathrm{~K} / \mathrm{min}$ & 723 & 1027 & 855 & 0.324 & 108 & 38.99 \\
\hline $30 \mathrm{~K} / \mathrm{min}$ & 743 & 1051 & 867 & 0.284 & 157 & 37.11 & $30 \mathrm{~K} / \mathrm{min}$ & 739 & 1034 & 882 & 0.317 & 111 & 37.42 \\
\hline $40 \mathrm{~K} / \mathrm{min}$ & 791 & 1058 & 898 & 0.295 & 145 & 35.85 & $40 \mathrm{~K} / \mathrm{min}$ & 774 & 1048 & 933 & 0.247 & 146 & 34.28 \\
\hline
\end{tabular}

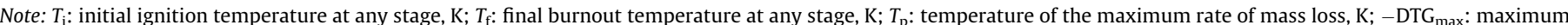
mass loss rate at any stage, \%/K; HTZ: full temperature width at half-maximum of the value of $-\mathrm{DTG}$ max $\mathrm{K}_{\text {; }}$ ML: total mass loss at any stage, \%. 
the value of ML for CP and SP was gradually increased from 5.975\% and $5.346 \%$ to $7.103 \%$ and $5.672 \%$, respectively. In stage II, it was increased from $47.16 \%$ for CP and $45.18 \%$ for SP to $48.24 \%$ and $49.37 \%$, respectively. On the contrary, the value of ML for CP and SP in stage III was gradually decreased from $38.36 \%$ and $39.31 \%$ to $35.85 \%$ and $34.28 \%$, respectively.

\subsection{Kinetic analysis}

The characteristic parameters derived from the TG-DTG curves were used to determine the kinetic parameters such as apparent activation energy for combustion of CP and SP. Compared to model-fitting method such as Coats-Redfern or Freeman-Carroll, iso-conversional approach can determine the apparent activation energy without assuming the reaction model, thus eliminating the manifestation of "kinetic compensation effect" brought by a false assumption of reaction model via model-fitting methods. Therefore, kinetic analysis in this study was carried out using an iso-conversional method. The combustion process of microalgae is a typical heterogeneous solid-state reaction, and the global combustion reaction kinetics can be described as:

$\frac{d \alpha}{d t}=k(T) f(\alpha)$

where $T$ is the reaction temperature, $t$ is the reaction time, $f(\alpha)$ is the differential function of conversion, $\alpha$ is the mass conversion ratio, which can be determined as:

$\alpha=\frac{w_{i}-w_{t}}{w_{i}-w_{f}}$

where $w_{i}, w_{f}$ and $w_{t}$ are the initial mass of the sample, the residual mass at the end of combustion process and the sample mass at reaction time $t$ /reaction temperature $T \cdot k(T)$ is the reaction rate constant, which can be described by the Arrhenius equation:

$k(T)=A \exp \left(-\frac{E_{a}}{R T}\right)$

where $A$ is the pre-exponential factor, $\mathrm{s}^{-1}, \mathrm{E}_{\mathrm{a}}$ is the apparent activation energy, $\mathrm{kJ} \mathrm{mol}^{-1}, R$ is the gas constant, $8.314 \mathrm{~J}(\mathrm{~mol} \mathrm{~K})^{-1}$.

Eq. (1) can be converted into Eq. (2) expressed as:

$\frac{d \alpha}{d T}=\left(\frac{A}{\beta}\right) \exp \left(-\frac{E}{R T}\right) f(\alpha)$

where $\beta$ is heating rate $(\beta=\mathrm{dT} / \mathrm{dt})$.

The integration form of the Eq. (4) is:

$\int_{0}^{\alpha} \frac{d \alpha}{f(\alpha)}=G(\alpha)=\left(\frac{A}{\beta}\right) \int_{T_{0}}^{T} \exp \left(-\frac{E}{R T}\right) d T=\left(\frac{A}{\beta}\right) p(x)$

where $p(x)$ in Eq.(5) is known as the temperature integral. The temperature integral does not have an exact analytical solution in closed-form. However, it can be approximately calculated via different empirical interpolation formulas such as Luke, Broido, Doyle, MacCallum-Tanner and Krevelen-Heerden-Huntjens approximation.

The Flynn-Wall-Ozawa (FWO) method and Kissinger-AkahiraSunose (KAS) method are the two most common model-free methods for determining the kinetic parameters, which has been widely used in complex processes in terms of the decomposition of biomass (Tahmasebi et al., 2013). Doyle's approximation (Doyle, 1961) is the empirical approximation used by the FWO method, which is represented as:

$\int_{T_{0}}^{T} \exp \left(-\frac{E}{R T}\right) d T=\frac{E}{R}\left(0.00484 e^{-1.0516 u}\right)$

Combining Eqs. (5) and (6) and then taking the logarithm of both sides lead to the expression for FWO method (Ozawa, 1965): $\ln \beta_{i}=\ln \left[\frac{A E}{R G(\alpha)}\right]-2.315-0.4567 \frac{E}{R T}=C_{0}-0.4567 \frac{E}{R T}$

In terms of KAS method, the employed empirical approximation is the following expression:

$\int_{T_{0}}^{T} \exp \left(-\frac{E}{R T}\right) d T=\frac{E \beta}{R A T}$

Substituting of Eq. (8) into Eq. (5), and then taking the logarithm of both sides lead to the expression for KAS method (Kissinger, 1957):

$\ln \left(\frac{\beta_{i}}{T_{p i}^{2}}\right)=\ln \left(\frac{A_{k} R}{E_{k}}\right)-\frac{E_{k}}{R T_{p i}}=C_{K}-\frac{E_{k}}{R T_{p i}}[i=1,2,3,4,5,6]$

Based on the Starink method (Starink, 1996), the expression of FWO method (Eq. (7)) and KAS method (Eq. (9)) can both be transformed into the same formula expressed as:

$\ln \left(\frac{\beta}{T^{S}}\right)=C_{S}-\frac{B E}{R T}$

where for the FWO method (Eq. (7)), $s=0, B=0.4567$; for the KAS method (Eq. (9)), $s=2, B=1$. It has been verified by Starink (Starink, 1996) that when the parameters of $s$ and $B$ are adjusted to 1.8 and 1.003 , respectively, the precision of this expression (Eq. (10)) is higher than either FWO or KAS method. Consequently, the Starink method can be represented as:

$\ln \left(\frac{\beta}{T^{1.8}}\right)=C_{S}-1.0037 \frac{E}{R T}$

The apparent activation energy was calculated from the slope and intercepts of the iso-conversional lines for a given conversion fraction from the TG curves of various heating rates. In the plot of $\ln \left(\beta / T^{1.8}\right)$ versus $1 / T$, the slope is $-1.0037 E / R$ from which the apparent activation energy can be determined. In this study, at different heating rates ranging from 10 to $40 \mathrm{~K} / \mathrm{min}$, nine levels of conversion fraction varying from $10 \mathrm{wt} . \%$ to $90 \mathrm{wt} . \%$ were used to determine the dependence of apparent activation energy on the conversion fraction during the combustion process. The regression lines of CP and SP are illustrated in Fig. 4. The variations of apparent activation energy at different conversion fractions for CP and SP are shown in Fig. 5.

Fig. 5 illustrated that the apparent activation energy of two low-lipid microalgae both varied greatly with different conversion fractions rather than keeping constant. Specifically, with increasing the conversion fraction from 10 to $90 \mathrm{wt}$.\%, the apparent activation energy of CP increased first from $51.96 \mathrm{~kJ} / \mathrm{mol}$ at $10 \mathrm{wt} . \%$ to 79.53 $\mathrm{kJ} / \mathrm{mol}$ at $40 \mathrm{wt} . \%$, then decreased to $55.59 \mathrm{~kJ} / \mathrm{mol}$ at $70 \mathrm{wt} . \%$. Finally, it slightly increased to $67.27 \mathrm{~kJ} / \mathrm{mol}$ at $90 \mathrm{wt} . \%$. Idris et al. (2012) investigated the combustion characteristics of palm biomass materials using iso-conversional Vyazovkin method. It was reported that the apparent activation energy of palm samples underwent the process a fall after a rise. The same behavior is observed in the literature (Ali et al., 2015), which investigated the variation of apparent activation energy of $N$. oculta at different conversion stages using iso-conversional FWO and KAS approach. Besides, the apparent activation energy of SP increased gradually from 68.51 to $91.06 \mathrm{~kJ} / \mathrm{mol}$. These results agree well with literature (Chen et al., 2012) reporting that the variation of apparent activation energy for $C$. vulgaris increased gradually based on FWO and KAS method. The different variation trends of apparent activation energy for CP and SP suggest that the combustion process of $\mathrm{CP}$ and SP may proceed with varied reaction mechanisms.

In addition, it can be seen in Fig. 5 that the average values of apparent activation energy for $\mathrm{CP}, 65.15 \mathrm{~kJ} / \mathrm{mol}$, is lower than that of SP, $84.29 \mathrm{~kJ} / \mathrm{mol}$. It is consistent with the TG-DTG-DTA curves 

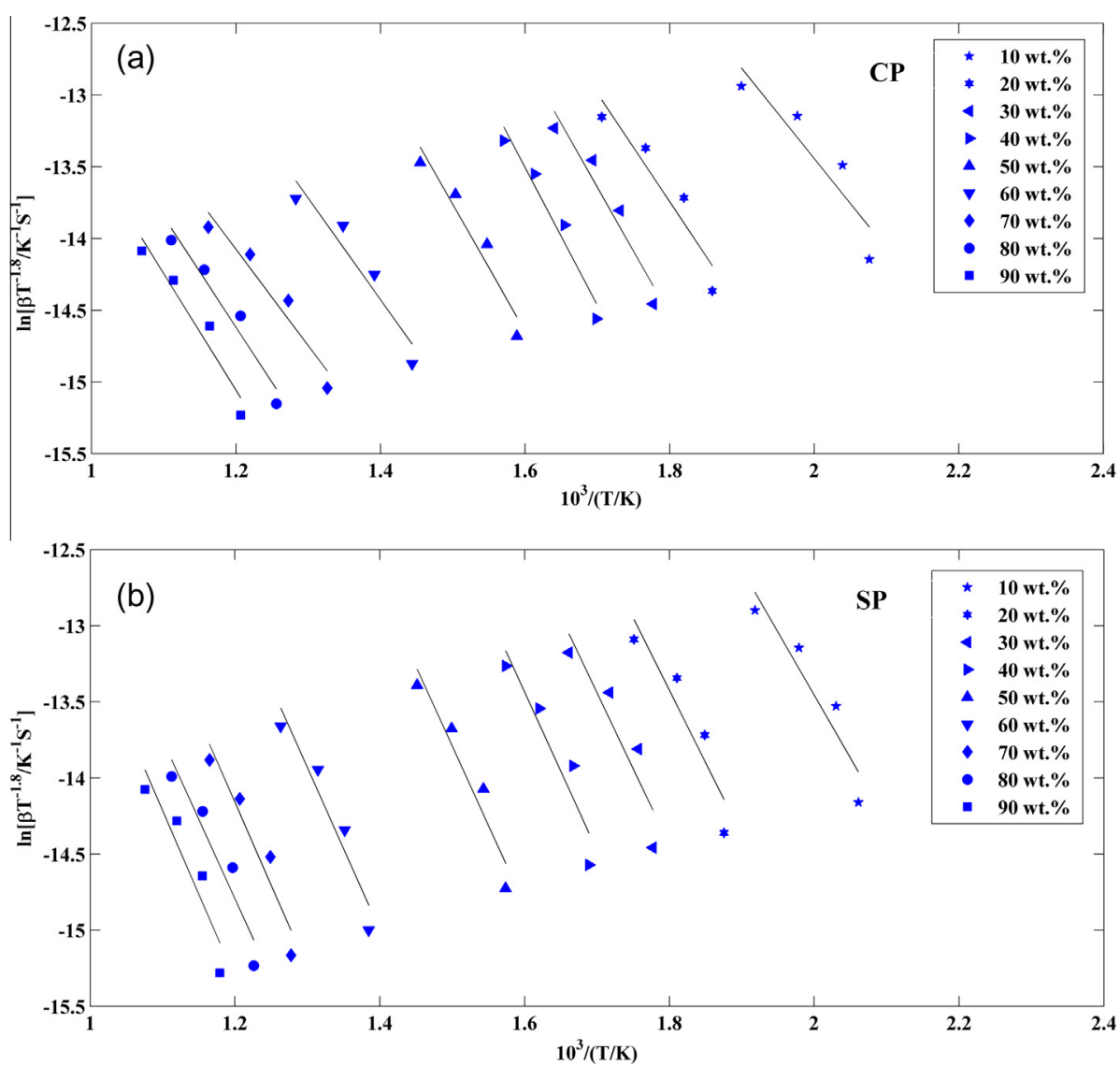

Fig. 4. Regression lines to apparent activation energy proposed by Vyazovkin approach for CP (a) and SP (b) at the heating rate of $10,20,30,40 \mathrm{~K} / \mathrm{min}$

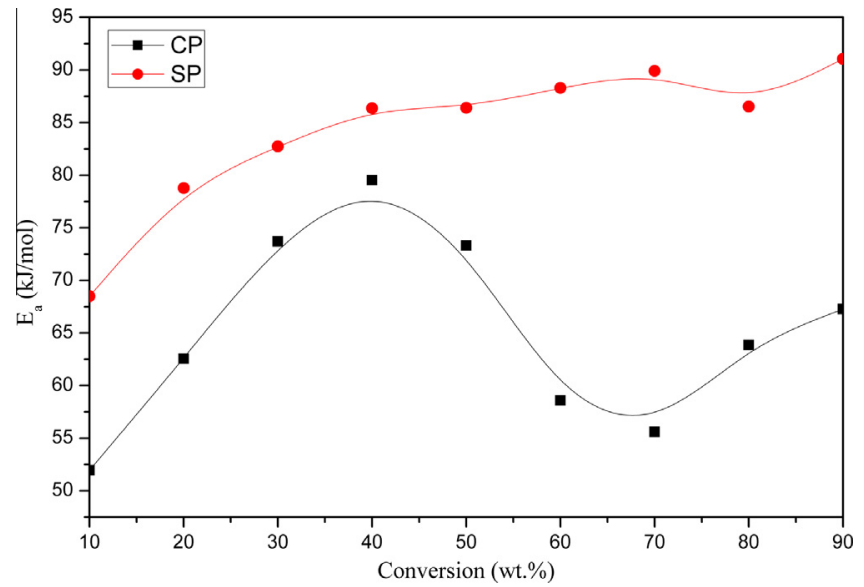

Fig. 5. Plot of apparent activation energy at different conversion fractions for $\mathrm{CP}$ and SP.

for $\mathrm{CP}$ and $\mathrm{SP}$ that the entire combustion process of $\mathrm{CP}$ is a bit earlier than that of SP. A reaction with lower apparent activation energy requires less energy to break down the chemical bonds between atoms and hence the reaction rate is faster. Thus kinetic analysis in the present study suggests that $\mathrm{CP}$ is preferable to SP in terms of thermochemical conversion for biofuel production.

\section{Conclusions}

Combustion characteristics of two low-lipid microalgae, C. pyrenoidosa and S. platensis were analyzed by TGA. Results indicated that three stages of mass loss were observed for two microalgae, and the whole weight loss during the combustion was both shifted to higher temperature zone with increasing the heating rates from 10 to $40 \mathrm{~K} / \mathrm{min}$. With the increment of conversion fractions from $10 \%$ to $90 \%$, the apparent activation energy of C. pyrenoidosa and S. platensis presented different trends and the average values of apparent activation energy for $C$. pyrenoidosa, $65.15 \mathrm{~kJ} / \mathrm{mol}$, is lower than that of S. platensis, $84.29 \mathrm{~kJ} / \mathrm{mol}$.

\section{Acknowledgement}

Financial support from the Chinese Academy of Sciences is greatly acknowledged.

\section{Appendix A. Supplementary data}

Supplementary data associated with this article can be found, in the online version, at http://dx.doi.org/10.1016/j.biortech.2015.01. 045.

\section{References}

Agrawal, A., Chakraborty, S., 2013. A kinetic study of pyrolysis and combustion of microalgae Chlorella vulgaris using thermo-gravimetric analysis. Bioresour. Technol. 128, 72-80.

Ali, S.A.M., Razzak, S.A., Hossain, M.M., 2015. Apparent kinetics of high temperature oxidative decomposition of microalgal biomass. Bioresour. Technol. 175, 569577.

Anastasakis, K., Ross, A.B., 2011. Hydrothermal liquefaction of the brown macroalga Laminaria Saccharina: effect of reaction conditions on product distribution and composition. Bioresour. Technol. 102, 4876-4883.

Branca, C., Di Blasi, C., 2015. Thermogravimetric analysis of the combustion of dry distiller's grains with solubles (DDGS) and pyrolysis char under kinetic control. Fuel Process. Technol. 129, 67-74. 
Chen, W., Ma, J., Zhang, Y., Gai, C., Qian, W., 2014. Physical pretreatments of wastewater algae to reduce ash content and improve thermal decomposition characteristics. Bioresour. Technol. 169, 816-820.

Chandrasekaran, S.R., Hopke, P.K., 2012. Kinetics of switch grass pellet thermal decomposition under inert and oxidizing atmospheres. Bioresour. Technol. 125, $52-58$.

Chen, C., Lu, Z., Ma, X., Long, J., Peng, Y., Hu, L., Lu, Q., 2013. Oxy-fuel combustion characteristics and kinetics of microalgae Chlorella vulgaris by thermogravimetric analysis. Bioresour. Technol. 144, 563-571.

Chen, C., Ma, X., He, Y., 2012. Co-pyrolysis characteristics of microalgae Chlorella vulgaris and coal through TGA. Bioresour. Technol. 117, 264-273.

Czernik, S., Bridgwater, A.V., 2004. Overview of application of biomass fast pyrolysis oil. Energy Fuel 18, 590.

Doyle, C.D., 1961. Kinetic analysis of thermogravimetric data. J. Appl. Polym. Sci. 5, 285-292.

EI May, Y., Jeguirim, M., Dorge, S., Trouvé, G., Said, R., 2012. Study on the thermal behavior of different date palm residues: characterization and devolatilization kinetics under inert and oxidative atmospheres. Energy 44, 702-709.

Fahmi, R., Bridgwater, A.V., Darvell, L.I., Jones, J.M., Yates, N., Thain, S., Donnison, I.S., 2007. The effect of alkali metals on combustion and pyrolysis of Lolium and Festuca grasses, switchgrass and willow. Fuel 86, 1560-1569.

Fang, X., Jia, L., Yin, L., 2013. A weighted average global process model based on twostage kinetic scheme for biomass combustion. Biomass Bioenergy 48, 43-50.

Gai, C., Zhang, Y., Chen, W., Zhang, P., Dong, Y., 2014. Energy and nutrient recovery efficiencies in biocrude oil produced via hydrothermal liquefaction of Chlorella pyrenoidosa. RSC Adv. 4, 16958-16967.

Idris, S.S., Rahman, N.A., Ismail, K., 2012. Combustion characteristics of Malaysian oil palm biomass, sub-bituminous coal and their respective blends via thermogravimetric analysis (TGA). Bioresour. Technol. 123, 581-591.

Jayaraman, K., Gökalp, I., 2015. Pyrolysis, combustion and gasification characteristics of miscanthus and sewage sludge. Energy Convers. Manage. 89, 83-91.

Kay, R.A., 1991. Microalgae as food and supplement. Crit. Rev. Food Sci. Nutr. 30, $555-573$.

Kissinger, H.E., 1957. Reaction kinetics in differential thermal analysis. Anal. Chem. 29, 1702-1706.

Liden, A.G., Berruti, F., Scott, D., 1998. A kinetics model for the production of liquids from the flash pyrolysis of biomass. Chem. Eng. Commun. 65, 207-221.

López-González, D., Fernandez-Lopez, M., Valverde, J.L., Sanchez-Silva, L., 2014. Kinetic analysis and thermal characterization of the microalgae combustion process by thermal analysis coupled to mass spectrometry. Appl. Energy 114, 227-237.
López-González, D., Fernandez-Lopez, M., Valverde, J.L., Sanchez-Silva, L., 2013. Thermogravimetric-mass spectrometric analysis on combustion of lignocellulosic biomass. Bioresour. Technol. 143, 562-574.

Magdziarz, A., Wilk, M., 2013. Thermogravimetric study of biomass, sewage sludge and coal combustion. Energy Convers. Manage. 75, 425-430.

Olafsson, P.G., Bryan, A.M., 1970. Evaluation of thermal decomposition temperatures of amino acids by differential enthalpy analysis. Mikrochim. Acta 5, 871-878.

Ozawa, T., 1965. A new method of analyzing thermogravimetric data. Bull. Chem. Soc. Jpn. 38, 1881-1886.

Phukan, M.M., Chutia, R.S., Konwar, B.K., Kataki, R., 2011. Microalgae Chlorella as a potential bio-energy feedstock. Appl. Energy 88, 3307-3312.

Rizzo, A.M., Prussi, M., Bettucci, L., Libelli, I.M., Chiaramonti, D. 2013. Characterization of microalgae Chlorella as a fuel and its thermogravimetric behavior. Appl. Energy 102, 24-31.

Sait, H.H., Hussain, A., Salema, A.A., Ani, F.N., 2012. Pyrolysis and combustion kinetics of date palm biomass using thermogravimetric analysis. Bioresour. Technol. 118, 382-389.

Saldarriaga, J.F., Aguado, R., Pablos, A., Amutio, M., Olazar, M., Bilbao, J., 2015. Fast characterization of biomass fuels by thermogravimetric analysis (TGA). Fue $140,744-751$.

Starink, M.J., 1996. A new method for the derivation of activation energies from experiments performed at constant heating rate. Thermochim. Acta 288, 97-104.

Stucki, S., Vogel, F., Ludwig, C., Haiduc, A.G., Brandenberger, M., 2009. Catalytic gasification of algae in supercritical water for biofuel production and carbon capture. Energy Environ. Sci. 2, 535-541.

Tahmasebi, A., Kassim, M.A., Yu, J., Bhattacharya, S., 2013. Thermogravimetric study of the combustion of Tetraselmis suecica microalgae and its blend with a Victorian brown coal in $\mathrm{O}_{2} / \mathrm{N}_{2}$ and $\mathrm{O}_{2} / \mathrm{CO}_{2}$ atmospheres. Bioresour. Technol. $150,15-27$.

Teng, H., Wei, Y.C., 1998. Thermogravimetric studies on the kinetics of rice hull pyrolysis and the influence of water treatment. Ind. Eng. Chem. Res. 37, $3806-$ 3811.

Williams, P.J.B., Laurens, L.M.L., 2010. Microalgae as biodiesel \& biomass feedstocks: review \& analysis of the biochemistry, energetics \& economics. Energy Environ. Sci. 3, 554-590.

Yu, G., Zhang, Y., Schideman, L., Funk, T., Wang, Z., 2011. Distributions of carbon and nitrogen in the products from hydrothermal liquefaction of low-lipid microalgae. Energy Environ. Sci. 4, 4587-4595.

Zhang, L., Duan, F., Huang, Y., 2015. Thermogravimetric investigation on characteristic of biomass combustion under the effect of organic calcium compounds. Bioresour. Technol. 175, 174-181. 